\title{
Algunos datos acerca de la cultura afrodominicana del siglo XVIII y una comparación etnográfica contemporánea
}

HELGA NEUMAYER

En la colonia española Santo Domingo del siglo XVIII había varias realidades distintas de la cotidianidad de la población negra, según el sector económico y social en que estaba envuelta.

\section{ESCLAVAS Y ESCLAVOS DOMESTICOS Y JORNALEROS}

En las ciudades los esclavos, pero sobre todo las esclavas se utilizaron como domésticos para diferente tipo de trabajos caseros, como se nota de una venta de una negra joven,

“... que la Esclava es joven, fiel y honrada, cose, laba, plancha, guisa y no tiene las más leve falta..." (A.G.I., Audiencia de Sto. Dgo. 925, Consulta, Sto. Dgo. 16.08.1806).

A veces los amos alquilaron sus esclavos a través de un jornal. El clérigo Antonio Sánchez Valverde, buen conocedor de la realidad colonial dominicana y adversario de dicha práctica nos cuenta:

"El abuso de tener Esclavos a jornal, demasiadamente estendido en nuestra América, inutiliza una gran parte de los pocos que tenemos...; que saca su jornal, la hembra, por lo regular, del mal. uso de su cuerpo, y los hombres regularmente del robo... y, en ganado una semana para satisfacer el jornal de dos, descansan la segunda. Fuera de lo más frequente es trampear a sus amos la mitad de los jornales asignados" (Sánchez Valverde (1785): 171 f.).

El jornal teóricamente era del amo de la esclava o del esclavo jornalero, pero partes del dinero podían ayudar a los últimos, a comprar 
su liberad. Y como menciona el cura, también existía la práctica de sacar jornal de las esclavas a través de prostitución, y ya en el año 1715 el arzobispo de Santo Domingo denuncia la práctica de los amos de mandar sus esclavas a la calle,

"...desnudas de cintura para arriba para mayor provocación" (Utrera, 1979: 303, cit. de Deive, 1980:310).

\section{ESCLAVAS Y ESCLAVOS DE PLANTACION}

La colonia española del siglo XVIII no tenía precisamente un florecimiento de producción de azúcar o de otros productos de plantaciones agrícolas esclavistas. Este sector casi no tenía importancia socio-económica. Casi todas las plantaciones estaban alrededor de la ciudad de Santo Domingo, donde residían los propietarios pertenecientes a la aristocracia burocrática (compare Cassá, 1987:120). Los casi únicos datos sobre la posible cotidianidad de aquellos se pueden sacar del "Código Negro Carolino" (1784).

Los esclavos de plantación sacaron su alimentación de un pequeño trozo de tierra, del "peculio", que tenían para cultivar frutas y verduras y criar aves; y de una ración semanal de parte del amo, que según una ordenanza del año 1768 tenía que ser,

"tres libras de carne, seis de casabe u otra cosa equivalente, como plátanos, patatas, etc., y a los muchachos que dejan el pecho, hasta la edad referida de diez años, con la mitad de dichos víveres" (C.N., 1974 (1784):119).

El sistema esclavista de la colonia entonces no contaba con mucha importación de africanos a través de comercio - ni legal ni ilegal-por eso los amos quieren aprovechar de la procreación endógena de los esclavos:

"La escasez de negros hace más urgente su necesidad de favorecer sus matrimonios, medio el más oportuno por otro lado de contener su fuga y suavizar su dura suerte y condición" (C.N. 1974 (1784): 215).

Pero en las plantaciones la procreación no parece ser tan fértil como sería útil para los esclavistas: 
"Siendo notable la esterilidad que se experimenta en las negras del campo, a proporción de las que viven en las poblaciones, se ha atribuido su causa a las enfermedades que contraen con las humedades del rocío del campo, cuando salen muy temprano a sus labores además de sus desórdenes que están expuestos en las haciendas donde hay mucho número de varones en comparación con las hembras. Tendrán pues, sus amos y mayordomos el mayor cuidado" (C.N. 1974 (1784): 216).

En los festivos el baile era una distracción favorecida de los esclavos, el código mencionado dice:

"Los placeres inocentes deben entrar en parte del sistema gubernativo de una nación en que la danza y la música hace la sensación más viva y espiritual, sus órganos son tan finos y delicados que enajenados con su armonía no sienten ni la fatiga que acaban de pasar en todo el día, ni la flaqueza de sus fuerzos consiguiente a los trabajos recios del cultivo empleando noches y días en este embeleso, sin pagar aún el tributo indispensable al dulce sueño que piden sus fatigados miembros. Esta ocupación análoga su carácter los distraerá en los días festivos de otras diversiones o concurrencias perjudiciales disipando en su espíritu la continua tristeza y melancolía que los devora y abrevia sus días y corregirá al mismo tiempo la estupidez propia de la nación y de la especie" (C.N. 1974 (1784): 229).

(Esta parte no nos muestra solamente un prejuicio racista sino cínico a la vez).

Respecto a lás creencias religiosas el código narra de ceremonias para los muertos:

"Prohibimos por esta razón bajo las más severas penas las nocturas y clandestinas concurrencias que suelen formar en las casas de los que mueren o de sus parientes a orar y cantar en sus idiomas en honor del difunto con mescla de sus ritos y de hacer bailes que comunmente llaman Bancos, en su memoria y honor de demonstraciones y señas (que anticipan regularmente que expiren) indicantes del infame principio de que provienen en muchas de sus castas, singularmente en los minas y carabalies de que hay el mayor número es a saber el de la Metempsicosis, aunque adulterada, o transmigración de las almas a su amada patria que 
es para ellos el paraiso más delicioso. Por lo cual se deberá formar un breve tratado moral, dirigido a desterrar en los negros sus erróneas pero bien arraigadas nociones e ideas de las divinidades de su patria, según sus diferentes castas que varían igualmente en sus ritos" (C.N. 1974 (1784): 164).

Los "bancos de muerto", conmemoración de la persona difunta al cabo del primer hasta séptimo año después del fallecimiento, existe hasta hoy día en ciertas zonas rurales y suburbanos del sur de la República Dominicana; las características de la celebración, el toque de atabales, las salves para la virgen, y los conceptos de la relación de vivos y muertos son una tradición netamente africana.

\section{ESCLAVOS HATEROS}

Una cotidianidad totalmente diferente a los anteriormente mencionados tenían los esclavos hateros, viviendo aislados en los muchos hatos y hatillos, ganaderías extensivas que había en todo el territorio de la colonia del siglo XVIII.

En los vastos parajes de la isla se criaban vacas y cerdos extensivamente y había que cazarles para el usufructo de sus carnes, su piel o capturales para venderles en vivo, muchas veces en contrabando a los vecinos de Saint-Domingue, la colonia francesa que carecía de carnes entonces.

Un hato no necesitaba mucha mano de obra y así muchas veces trabajaban solamente dos o tres esclavos juntos con su amo en la misma tarea.

En el siglo XVIII esta "producción era la más importante, a base de la esclavitud feudal-patriarcal, predominando en las regiones fronterizas, en el sur, en el noroeste y en el este" (Cassá, 1987:120).

El clérigo Sánchez Valverde nos describe un poco de la vida de aquellos hombres aislados:

"Los Pastores de la Española que se ocupan en la crianza de los animales, tienen que madrugar todos los días y salir descalzos, pisando el rocío o el lodo, en busca del Caballo que han de montar para sus correrías. Como la Caballería se mantiene de su diligencia, suele estar muy distante o tal oculta entre los matorrales y arboledas, que viene a costar mucho trabajo el encontrarla. Condúcela el Pastor a la casa después aparejarla, se desayuna con un plátano asado, si le tiene y una taza de Gengibre o Café, que es 
todo su alimento hasta la hora que vuelve. Así desayunado, monta a caballo y va sufriendo los ardores del Sol o la molestia de las lluvias por bosques, montes o sabanas; ... sale el Montero descalzo: a pie por lo regular, con una lanza y sus Perros. Si va a caballo, tiene que dejarle a la entrada del bosque o montana, porque son impenetrables si no es a pie. Aún así ha de hacer mil contorsiones con su cuerpo para entrar y poder seguir la caza. Suelta uno, dos o más Perros, a los cuales les enseña a rastrear la Pieza. Al ladrido de éstos corre el Pastor con su lanza, rompiendo ramas, pisando espinas y tropezando con ganchos, en que quedan los arapos de la camisa o calzones, y no pocas veces la carne...

El lecho es un simple cuero de vaca, lecho sobremanera sano en un país tan cálido. Algunos lo forman con una especie de encanizado en palos soportado por algunas eslacas. De este modo se procuran una cama sobre la cual se tienden envueltos con un pedazo de tela, pero esta tela está siempre escrupulosamente doblada durante el día y es la hamaca tejida en forma de red con cáñamo proveniente de pita... donde ellos reposan durante los muchos momentos que ellos conceden cada día a la pereza y al ocio, en buena parte legitimados por el ardiente calor del suelo que ellos habitan" (Sánchez Valverde, 1947 (1785): 186-197).

Las tareas de los hatos eran trabajos individuales y el control del esclavo no podía ser muy riguroso. No obstante el trabajo forzado era parte substancial del hato y el esclavo era un ser sin bienes y derechos y cuando perdió la capacidad de trabajar su existencia dependía totalmente del arbitrio del amo:

"Nada nos es más extraordinario que de ver alrededor de ellos viejas personas condenadas a vivir en una escualidez extrema, de las producciones vegetales y poco alimenticio del suelo, ellos deben morir desde el momento que no puedan hacer uso de todas sus fuerzas para servir a sus amos; igualmente leales a los más malos estos fieles, leales, bondadosos amigos del hombre llevan frecuentemente largas cicatrices que atestiguan los crueles castigos que les hacen a menudo sus amos, necesariamente duros y siempre a su lado, y que jamás abandonan, solamente cuando se entregan al descanso durante la noche" (Deive cit. Vicent, 1980: 347f.). 


\section{LOS CIMARRONES, ESCLAVAS Y ESCLAVOS ALZADOS}

Otra realidad negra de la Española del siglo XVIII era la de los alzados, mujeres y hombre esclavos que se tomaron la libertad de huir el sistema esclavista y vivir una vida propia refugiados en los bosques espesos de las montañas de la isla.

En el siglo XVIII, época de gran florecimiento económico de "Saint-Dominique", (la colonia francesa en la isla), la Sierra del Bahoruco fue refugio para los esclavos "franceses" y, en parte, también de esclavos "españoles" de Santo Domingo. Estos hombres y mujeres, quienes en realidad eran más bien africanos que "franceses" o "españoles", necesitaban un sitio lejano de cualquier tipo de vigilancia y administración colonial, y este amparo les ofrecía la Sierra aquella, entonces ya frontera con la colonia francesa igual como hoy en día con Haití.

En el Archivo de Indias se nos conserva una "lista individual de los negros de ambos sexos existentes en el Maniel de Neyba en 28 de Mayo de 1785" (A.G.I., Audiencia de Sto. Dgo. 1102, Resolución del Consejo de Indias, 12.12.1787): se trata de un asentamiento (maniel) de negros en la Sierra del Bahoruco, con 127 personas residentes en dicho maniel, 37 hombres y 38 mujeres adultos, 31 niños y 21 niñas. De los hombres había nueve que ya nacieron en el mismo maniel, de las mujeres 18. De los hombres adultos se clasifican siete como solteros, los otros tienen no más que una esposa en la lista oficial, pero hay mujeres adultas con bebés, clasificadas de solteras; como hay un equilibrio entre los dos sexos respecto a las mujeres y hombres adultos, podría haber habida la posibilidad de poligynía.

A través de un testimonio del gobernador Azlor, quien en el año 1768 hizo una expedición contra los cimarrones del maniel, pero también a través de contactos posteriores del mismo siglo, sabemos un poco de la vida de los alzados. Sus asentamientos eran más o menos fijos, ellos tenían conucos (huertos en el bosque) y ganadería, cazaban y comerciaban a veces para obtener artículos de hierro y armas. No se puede describir su vida cotidiana exactamente, pero tal vez no era tan diferente de la cotidianidad de los pequeños campesinos dominicanos de épocas posteriores, con excepción de un hecho muy importante: a cada momento tenían que estar listos para defensa y fuga en caso de ataques de tropas coloniales.

Al mismo tiempo tenían una gran ventaja a los soldados españoles: tenían un gran conocimiento de las lomas, cañadas, arroyos, de las 
plantas y frutas del bosque, y la misma naturaleza del paraje les ayudabala defenderse, mientras las tropas coloniales sufría todo tipo de molestias, como narra el dicho Azlor:

"... pues como impuestos en todas aquellas malezas, en que escasamente aún el sol penetra, hallando refugios a cada paso, y ...la subsistencia, pues este se reduce a Palmas que llaman Manacla, y Cacheos, como también a otros raices silvestres, o Names, a que son acostumbrados, imposibilitando por estos medios el de... rendirles por necesidad: Bien al contrario, lo que hemos vistos ha sido que nuestra Tropa, y Milisia, se ha fatigado, y estropiado, y aun padecido mil miserias..." (A.G.I., Audiencia de Sto. Dgo. 1101, Testimonio del Gobernador al Rey, Sto. Dgo., 26.03.1768).

Por eso, aquellos habitantes del maniel no siempren eran objetos perseguidos, sino también sujetos de contratos con la administración colonial, como en los años 80 del XVIII, cuando se les ofrecía tierra para cultivar y habitar en "Arroyo Naranjo", paraje de la llanura de La Laguna de Cabral, a cambio de abandonar el maniel en las montañas. Algunos de ellos fundaron lo que hoy en día se llama "El Naranjo", pueblo, cuya característica específica consiste en los murales extraordinarios que pintan las Señoras en sus casas antes de Navidad (vea fig. 1).

Dos toponimias actuales señalan la presencia histórica de los cimarrones en el Bahoruco: "Maniel Viejo" y "Sabana de Maniel". Ambos pueblos están situados en un altiplano, rodeado de montañas, en cuyos declives se cultiva café como producto comercial, y donde los campesinos tienen sus conucos para la autosubsistencia. Los dos pueblos tienen fuentes de agua. El ganado se cría de una manera semi-extensiva, es decir, vagabundeando por las lomas con el limitado control de bastas alambradas.

Al noroeste del altiplano se encuentra un Graben, el "Hoyo de Pelempito" sin arroyo o fuente de agua permanente por la rápida infiltración del agua hacia el subsuelo, dejando solamente pequeños depósitos en el seño del piso calizo. Este subclima seco impide agricultura y ganadería, pero es región de caza para los monteros procedentes de varios pueblos de diferentes lados de la Sierra del Bahoruco. Estos cazadores conocen las pequeñas cisternas naturales en la caliza donde tomar el agua para sobrevivir. Para sus cacerías de más de un día tienen una cueva de pernoctar con una cama improvisada con palos y donde cocinan. Los hombres cazan puercos cimarrones, cabras y guineas. Llevan escopeta y cuchillo grande y pequeño. Portan 
además "tirapiedras" para derribar pájaros. En el límite oeste del Graben se encuentra la "Cueva de los Retratos" con arte rupestre (vea fig. 2) cuyo origen podría tener tal vez una relación con los cimarrones de la región, como lo califica también el arqueólogo dominicano Abréu:

“... las pictografías que encontramos en la Cueva de los Retratos presentan una hechura atípica con relación a las que normalmente aparecen en otras cuevas de la isla (de origen indígena, anota), lo que nos inclina a asociarlas a las actividades cimarronas. La diferencia más notable es el uso de ceniza apelmazada para el trazado de las pinturas, lo que les confiere un aspecto de alto relieve. El tocado que presentan algunas de ellas, así como las orejas, no son típicas en las figuras antropomorfas indígenas... En el caso de las pictografias blancas de la Cueva de los Retratos... vemos la utilización de los medios supernaturales (magia, rito, conjuro) dirigidos a los blancos perseguidores con el objetivo de hacer fracasar el propósito de hacer retornar a los cimarrones al cepo esclavista.

Una tesis que sólo un fechamiento riguroso podría confirmar o desmentir" (Abréu/Neumayer, 1991: 8).

Todas estas diferentes realidades negras, la de esclavas y esclavos domésticos y jornaleros, de las plantaciones, la del esclavo hatero y la de mujeres y hombre cimarrones, se cambiaron con los acontecimientos históricos del cambio del siglo, con la revolución haitiana; con la abolición de la esclavitud y los grandes cambios económicos en el siglo XIX, cuando la ganadería perdió por el comercio de madera preciosa y la producción agrícola intensiva de azúcar, cacao, tabaco y café. Pero hay creencias religiosas, tradiciones de la música y del baile que tendrán su origen en aquella época colonial del XVIII y han sobrevivido de alguna u otra forma hasta hoy día.

\section{BIBLIOGRAFIA}

Archivo General de Indias (A.G.I.), Sevilla, España.

Codigo Negro Carolino (C.N.), (1784); ed.: Malagón Barceló (1974), Santo Domingo. Rep. Dominicana.

SANCHEZ VALVERDE (1785): Ideal del valor de la Isla Española; ed.: Utrera (1947), Santo Domingo. Rep. Dominicana.

ABREU/NEUMAYER (1991/08/24): Cultura cimarrona en la Sierra de Bahoruco; en: Hoy, Santo Domingo. R. Dominicana. 
CASSA (1987): Historia Social y Económica de la República Dominicana, Tomo I, Santo Domingo. R. Dominicana.

DEIVE (1980), La esclavitud del negro en Santo Domingo, Santo Domingo. R. Dominicana.
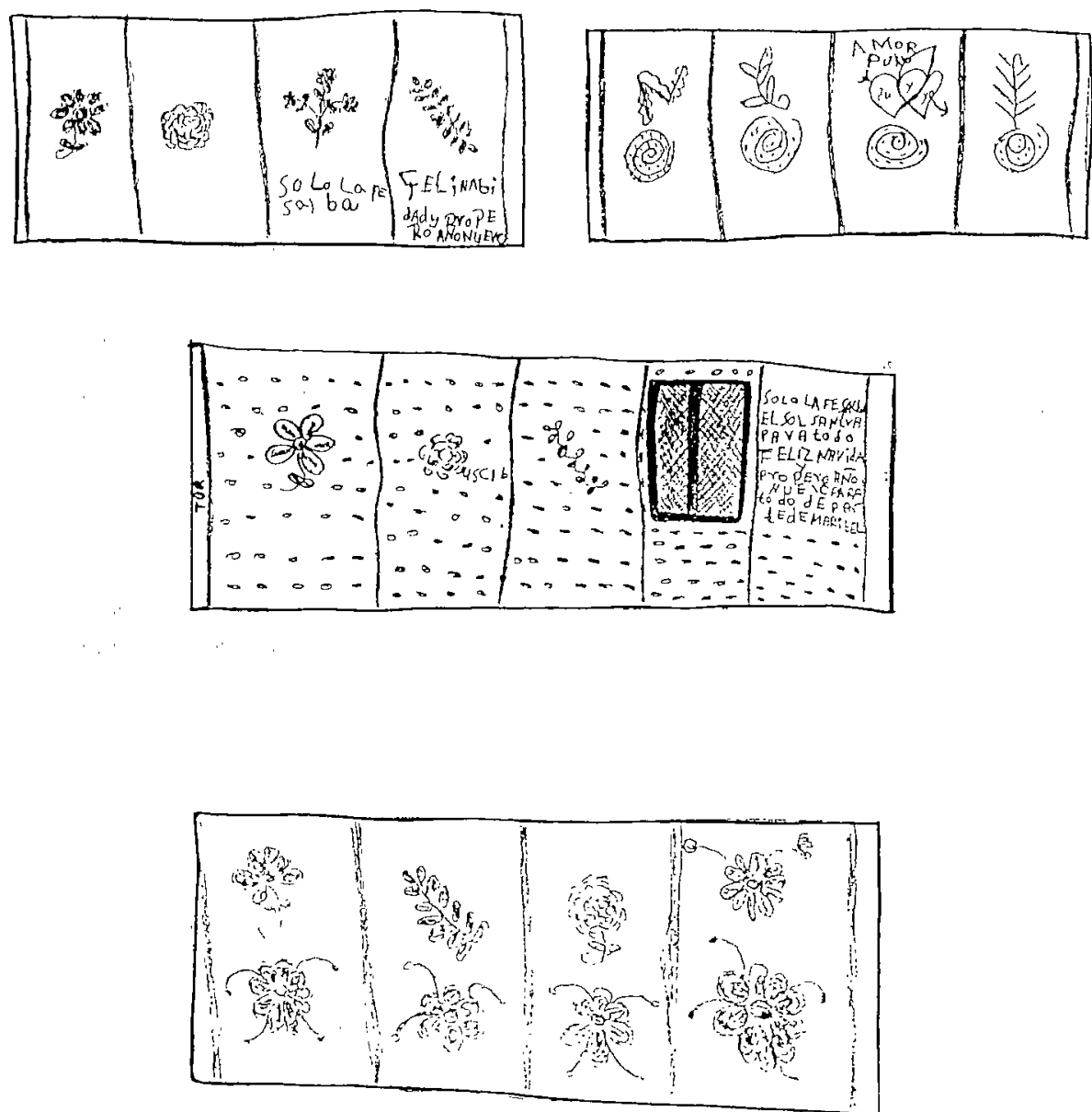

Fig. 1: Croquis de murales de cuatro casas diferentes de "El Naranjo", Provincia Barahona, Rep. Dominicana. Antes de Navidad las señoras pintan los muros barrosos de sus casas con ornamentos religiosos de carácter floral y con parabienes correspondientes a las Pascuas de Navidad. Varios colores. Altura: $2 \mathrm{~m}$. 


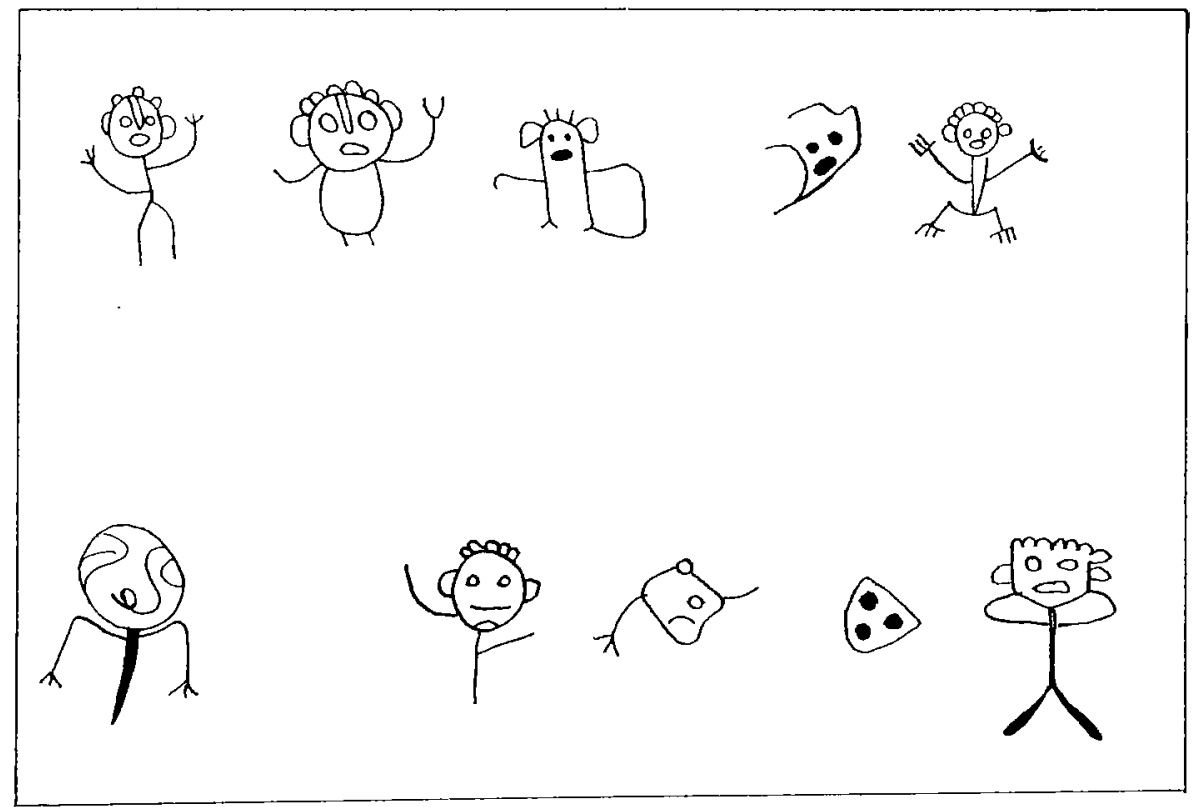

Fig. 2: 10 pictografias de la "Cueva de los Retratos", Hoyo de Pelempito, Provincia Pedernales, Rep. Dominicana. Blancos a base de ceniza apelmazada. Alturas: entre 9 y $50 \mathrm{~cm}$. 